\title{
Features of the Development of Regional Transport Models
}

\author{
P.V. Loginov, A.N. Zatsepin and V.A. Pavlov
}

\begin{abstract}
Improvement of the Russian legislation in the field of strategic and territorial planning administrative units of the Russian Federation repeatedly increased the demand for specialists in the analysis and forecasting of social and economic development of the state authorities and local government entities, in the modern tools of transport modeling. The spectrum of regional facilities in their size and in their administrative status multivariable tasks for problem solving with traffic. In this condition, important thing is the development of building technology of transport models that have universal possibilities for different types of the researching area. Currently, the best developed methods are methods of transport models of cities and agglomerations. Meanwhile, also important thing is using transport modeling as a tool for the planning and development of federal and regional transport systems. In the development of regional transportation model should be taken into attention, the specificity of the transport system functioning in regional level, which does not allow to use the methodological apparatus intended for the development of urban models. The proposed methodological approaches can be used in the development and updating of the regional transport models, helping to reduce the cost of the process and being effectively applied in the researching areas on any administrative level.
\end{abstract}

Keywords Transport modeling - Regional transport model • Matrix of correspondence

P.V. Loginov $(\bowtie) \cdot$ A.N. Zatsepin · V.A. Pavlov

"Kvantex", Moscow, Russia

e-mail: office@kvantex.ru

A.N. Zatsepin

e-mail: 6234914@gmail.com

V.A. Pavlov

e-mail: office@kvantex.ru

(C) The Author(s) 2018

K.V. Anisimov et al. (eds.), Proceedings of the Scientific-Practical Conference

"Research and Development - 2016", https://doi.org/10.1007/978-3-319-62870-7_29 


\section{Introduction}

Currently around the world there is a tendency of development of the regional transport systems. This process is accompanied by an increase in economic activity of the population, the redistribution of traffic flows, the formation and the growth of urban centers, etc. So, these processes significantly affect on the transport mobility of the population, analysis reveal the main directions of development of economy and improvement citizen's standard of living. For implementation of the most efficient and less labor-intensive analytic, we need to develop new methodologies and tools to assess the processes that accompany the development and changes in transportation systems. Planning the development of transport systems in the Russian Federation is carried out on three levels: federal, regional, and local. If the methodology of the transport models of cities and agglomerations sufficiently developed by now [1, 2], the development of regional models is an actual scientific problem.

The authors had a task to develop the concept of information technology of macromodel transport systems building for typical Russian region and modeling methods of existing and forecasted traffic flows.

Currently, the technology of building information models in different levels of transport systems has a similar typology. But these models look like a unique product of scientific researching in the annex to the specific object of research.

Creating of a generic technology for building the transportation system model of region requires certain restrictions in raw data and the results of further processing and calibration. The main objective of the developed technologies is the creation of sufficiently reliable information macromodel of regional transport system in the existing information and resource constraints. This model should allow forecasting of the transport system development. Increasing of individual objects' reliability or areas of the region's transport system and the creation of multimodal logistics facilities are the tasks of the next level, and their solution depends on the uniqueness of a particular area.

Transport modeling is a modern tool for decision-making in the systems of transport planning on different levels. The demand of this tool in the development of transport systems is stable and has a high level. In recent years, the need of transport models development repeatedly increased. It is caused by the introduction of new requirements for the development of projects and schemes of the organization of traffic in the territories of municipalities of the Russian Federation, which establishes mandatory construction of transport models in the design process. Unfortunately, this tool is expensive: the development of the transport model-is large scientific and research work, which requires the collection and processing of significant volumes of raw data. The using of developed transport models require special knowledge and training, that makes them difficult to use. Nowadays a lot of the administrations of municipalities in the Russian Federation do not have this tool and do not use it for solving problems of transport planning.

This situation is a serious problem that requires a comprehensive approach to solution. One of the costly stages in the development of the transport model is the 
stage of collecting raw data. Foreign colleagues from developed countries can do it easier because of a permanent monitoring of the transport system and periodic sociological research usually conducted in their countries [3]. The necessary data are available partly like scattered and not systematic in large number of administrations of the Moscow Area in the Russian Federation.

Thus, one of the urgent tasks of the work is searching for alternative sources of data.

This work covers the following aspects of the authors in the framework of applied research:

- Development of methodological approaches to the construction of a regional transport model of the Russian Federation typical region;

- Searching for the original data sources that reduce the cost of construction of regional models and the development of methods of pre-treatment.

\section{Defining the Concept of Choosing the Optimal Set of the Main Components of Information Technology of Macro Models of Typical Russian Region}

The authors selected standard algorithm that include following components:

- baseline data of transport supply and demand;

- model of transport demand. A modified classic four-step method of calculation used for creating the model. The advantages of the chosen model are accurately describing all the stages of transport demand formation with low requirements for computing power of personal computers;

- model of the transport supply;

- distribution model of transport demand for offer.

For creation of these components, the authors have developed a hardware-software complex of transport region system modeling (PAK MTSR). This complex will automate the collecting and processing information of traffic flows process, save and process the basic data of the characteristics of the roads; the proposed modeling technology of transport supply and demand can be implemented with the help of specialized software.

The complex also has a high mobility and computing power. It is important in region conditions. In addition, to ensure the adequacy of the generated transport model and its relevance, the creating of the typical Russian region information macromodel technology includes these procedures

- calibration of the regional transport models;

- evaluation of the quality of the final transport model version with predetermined criteria;

- updating of the model according to source data. 
Model calibrating result is conformity of raw data and results of modeling. Difference of approaches to building macromodel of a typical Russian region:

- creation of a model with "from global to local" method with using federal strategies for the development of transport systems;

- initialization of supply and demand models level with using specifics of the region;

- using of mobile PAK MTSR equipped with sensors measuring vehicle flows.

Transport macromodel technology conception has been developed as a result of science researching that described in the current work.

\section{The Features of the Calculation of Transport Demand Within the Regional Model}

The main differences in approach to the modeling regional transport system are identified on the phase of the modeling transport demand. For models of the cities and agglomerations, the most intensive are some labor correspondences. Herewith a pendulum character of this kind of correspondence makes great relevance of transport models, which are developed for morning or evening peak period.

In the scale of the region (subject of the federation), the most intensive become business travels and freights and their distribution of time makes daily allowance transport model more actual. It should be noted, that the labor correspondences also shall be calculated in the consisting of the regional model, but their temper is perfectly expressed by localization in the districts of big localities, that result into causing point loads on the regional transport system at all. The specific layer of the demand makes significant load on the regional transport system that was made by recreational correspondences. The specificity includes both the distribution of time (the most intensive periods are weekends and holidays and also on the vacation time) and the susceptibility to the influence of external factors, for example weather. The other layers of demand, that are connected with a rides to the medical institutions, for example, makes quite low load and cannot be considered in the modeling the regional transport model. So business, labor and freights correspondences should be considered first within the regional transport model (in the regions of big localities).

The using of this information gives the most accurate results in the case of the transport of zoning on the borders of MO, which is quite acceptable, and sometimes even excessively when building a regional transportation model.

To calculate the matrix of correspondences for the business and cargo segments, the authors propose the use of as input data of the tax reporting, presented in free access at the website of the Federal tax service of the Russian Federation [4]. All provided reports each year aktualisierte and formed within the context of 
municipalities. The use of this information gives the most accurate results in the case of the transport of zoning on the borders of MO, which is quite acceptable, and sometimes even excessively when building a regional transportation model.

On the basis of the tax on property of organizations (NIO), about the tax base for the unified tax on imputed income for certain types of activities (UTII), the tax base for the tax paid by taxpayers in connection with the application simplified tax system (STS) can be obtained by estimating the number of economic entities in the context of municipalities. To assess the composition of the truck fleet can be used information about the tax base and structure of charges for the transportation $\operatorname{tax}(\mathrm{TN})$.

Accordingly, the calculation of the matrices of freight and business correspondence is based on the conclusion that their number is on average proportional to the number of business entities and the allocation is based on a "gravity" principle.

The calculation of the matrices of labor correspondence methodologically refined [1] and requires the collection of data on employment and working population in the context of the transport areas, in the present embodiment, in the context of MO. The greatest difficulty causes the job assessment, because the authorities are at best accounting for large- and medium-sized enterprises.

To estimate the number of jobs in the context of MO, the use of report 5-NDFL the Federal tax service of the Russian Federation- "the Report on tax base and structure of charges to tax on income of physical persons, withheld by tax agents" [4]. It contains data on the number of individuals paying the tax to incomes of physical persons (NDFL), which corresponds to organized workplaces.

Thus, the use of tax statements as the source data allows to calculate the matrix of correspondences for all major segments of demand within the regional transport model.

\section{Optimization of Organization Methods of Developing and Updating Regional Transportation Models}

Regional road network consists of roads of Federal, regional or intermunicipal and local value. Technical condition of the road network in most areas beyond the regulatory framework and is subject to annual random fluctuations in the spring. The volumes of necessary repair work within the region do not allow to neglect this factor in transport modeling. Thus for developing and updating regional transportation models require the rapid collection of information about the condition of the road network.

In the absence of monitoring data of the intensities of traffic flows on major regional highways, this task is necessary to solve the developer transport model. Across the region it is necessary to conduct a substantial amount of measurements of the intensities of traffic flows, it is required to consider possible variations of values depending on weekday or weekend and time of year.For solving the mentioned problems, we propose the use of the above specialized hardware-software 


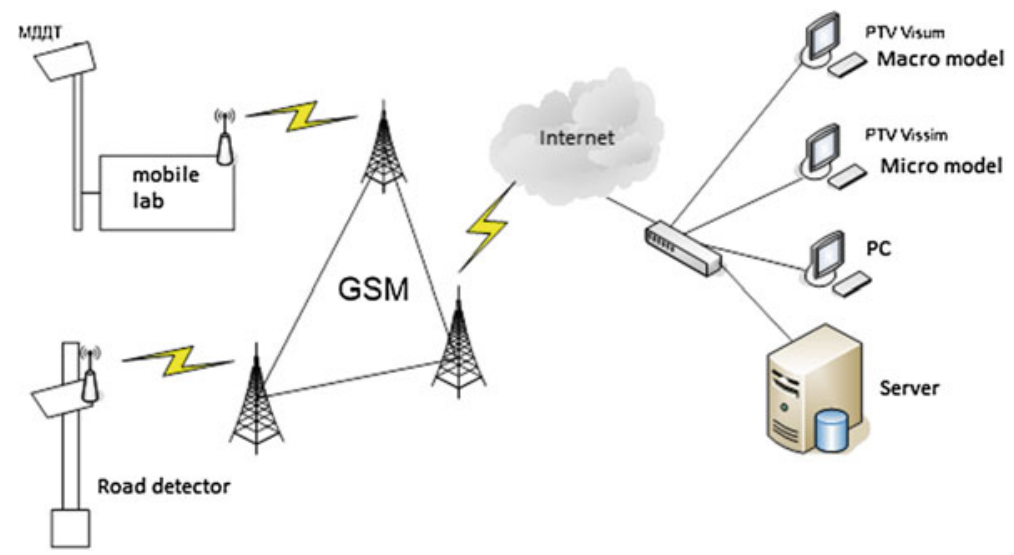

Fig. 1 Structural scheme of PAK MTSR

complex simulation of the transport system of the region. Figure 1 shows a block diagram of the PAK MTSR.

PAK MTCP consists of a mobile complex which is intended for carrying out measurements, and stationary complex, which is used for data processing, development and calibration of traffic models.

The mobile complex is based on a mobile laboratory, for example, KP-514CMП produced by "Spetsdortekhnika" (Saratov, RF) [5], which collects data on the characteristics and condition of the road network. Measuring the intensities of traffic flows in the composition of the mobile complex includes the sensors of traffic. Stationary sensors traffic (SDT), for example models of Hand-Wave-A-01 [6], it is proposed to use for long-term monitoring of traffic flows. For the operational refinement of data measurements of the intensities of traffic flows using mobile sensors, traffic (MDDT), for example, ThermiCam ETH 10-7042 [7].

As you collect the mobile set of input data is transmitted to the server PAK MTSR, where a database of transport modeling. In the process of developing a regional transport model to the work of the mobile complex adjustments can be entered. For example, if essential differences of settlement and natural (real) part of road network have been noted, goal is set to mobile complex operator to do addition measurements.

Application PAK MTSR for tasks collect baseline data in order to build and update regional transportation models to improve simulation quality and reduce development costs. These advantages are achieved through the use of the developed transport model, the most complete and current source of data, and optimization procedures for obtaining them. 


\section{Conclusions}

Today the Russian Federation significantly stands behind developed countries in transport system development; therefore this issue is one of the top-priority for the state. Optimal transport system development on the federal, regional, and field levels is possible with the usage of up-to-date instruments of transport modeling in making management decisions.

In this work, methodological approaches to the development of the regional transport models are suggested, their usage allows to optimize the process of source data acquisition as it is the most cost-based stage during the development. The resulting reduction in expenditure for the development of the regional transport model will facilitate a wider usage of the instrument for the transport system development on the regional and federal levels.

\section{Gratitude}

The studies were conducted in accordance with the Agreement No. 14.588.21.0001 from the 26 September 26, 2014. With the Ministry of education and science of the Russian Federation on granting subsidies in the execution of works on the theme "creating technologies of construction of information models of transport systems in the model region of Russia, including the development of algorithm for calculations of the efficiency from exploitation of toll and other roads of Federal, regional and local level, on the basis of the program complex world level PTV Vision ${ }^{\circledR}$ VISUM/VISSIM (Germany)" together with "A+S Consult GmbH Forschung und Entwicklung" (Dresden, Germany) in the framework of applied research in priority areas with the participation of research organizations of member countries of the EU in the framework of activity 2.2 of the Federal target program "Research and development on priority directions of development of scientific-technological complex of Russia for 2014-2020. Unique identifier of applied research (project) RFMEFI58814X0001.

Acknowlegements The studies were conducted with the financial support of the state, represented by the Ministry of Education and Science of the Russian Federation № 14.588.21.0001 Agreement of 26 September 2014 Unique identifier for Applied Scientific Research (project): RFMEFI58814X0001.

\section{References}

1. Aliev, A.S., Strelnikov, A.I., Shvetsov, V.I.,Shershevskaya, Yu.z.: Simulation of traffic flow in a major city with an application to the Moscow agglomeration. Automatic. Telemech. 11, 113-125 (2005)

2. Safronov, E. A.: Transport system of cities and regions: a training manual. pp. 12-25. Publishing house ASV (2005). ISBN 5-93093-345-6 
3. TUD—Forschungsprojekt "Mobilität in Städten—SrV" [Electronic resource]-Mode of access: https://tu-dresden.de/die_tu_dresden/fakultaeten/vkw/ivs/srv/. Free. The title. Screen

4. Stat reporting [Electronic resource]—Mode of access: https://www.nalog.ru/rn62/related_ activities/statistics_and_analytics/forms/. Free. The title. Screen

5. Comprehensive road laboratory "Track" [Electronic resource] - Mode of access: http://sdtech. ru/store/lab/trassa/trassa.html. Free. The title. Screen

6. Hand-Wave-A-01. ДСШ01П [Electronic resource]-Mode of access: http://strelka-wave.ru/ product/arrow-wave-a-01-dcw01p.html. Free. The title. Screen

7. ThermiCam Specifications [Electronic resource]-Mode of access: http://www.flir.ru/cs/ display $/$ id $=61844$. Free. The title. Screen

Open Access This chapter is licensed under the terms of the Creative Commons Attribution 4.0 International License (http://creativecommons.org/licenses/by/4.0/), which permits use, sharing, adaptation, distribution and reproduction in any medium or format, as long as you give appropriate credit to the original author(s) and the source, provide a link to the Creative Commons license and indicate if changes were made.

The images or other third party material in this chapter are included in the chapter's Creative Commons license, unless indicated otherwise in a credit line to the material. If material is not included in the chapter's Creative Commons license and your intended use is not permitted by statutory regulation or exceeds the permitted use, you will need to obtain permission directly from the copyright holder.

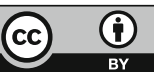

